\title{
Impact of Body Mass Index on Implantation Rate in ICSI Cycles
}

\author{
Osama Alsaied Ali, Bassem Ragab Abdel-Aziz, \\ Abdallah Mohammed Ahmed Alsenbawy \\ Obstetrics and Gynecology Department, Faculty of Medicine, Al Azhar University \\ * Corresponding author: Abdallah Mohammed Ahmed Alsenbawy, E-mail: Mido158015@gmail.com
}

\begin{abstract}
Background: obesity and overweight are recognized as a growing global health problem Worldwide, prevalence of overweight or obesity, defined as an adult body mass index (BMI) of $25 \mathrm{~kg} \mathrm{~m}^{2}$ or greater. Patterns of overweight and obesity differ between countries, regions and by country income, with overweight or obesity more prevalent among men in developed countries and among women in developing countries. Aim of the Work: this study aimed to evaluate the impact of female increased body mass index (BMI) on implantation rate and clinical pregnancy in women undergoing ICSI cycle. Patients and Methods: this is a retrospective study conducted on a total of 400 cycles of assisted reproduction treatment has been evaluated from Orabi IVF Centre and Mit_Ghamr IVF Centre. Data recruited from patient files from January 2016 to July 2018 who did ICSI trial during this period. Patients who included in our study were sub divided into 2 groups according to BMI: $\mathbf{1}^{\text {st }}$ group: normal weight with BMI between 18 and $24.9 \mathrm{~kg} / \mathrm{m} 2$. (200 case), $2^{\text {nd }}$ group: overweight and obese women $\geq$ $25 \mathrm{~kg} / \mathrm{m} 2$ (200 case).Results: we showed that overweight and obese infertile women had a higher basal serum FSH, LH and estradiol levels than normal weight women. In our study group the duration of infertility was progressively higher as BMI increased. The two groups were comparable regarding female age were not statistically different in both groups. The duration of infertility showed no significant difference between the two groups. As in group (1) it range from 10-17 years with median duration of 6 years, while in group (2) it range from 0.5-23 with median duration of 5 years this result a significant difference with $\mathrm{p}$ value (0.057).Conclusion: female overweight and obesity appeared to have deleterious effects on ovarian response to stimulation in women undergoing IVF and implantation rate. Moreover, female obesity compromised IVF outcome.
\end{abstract}

Keywords: Body Mass Index, ICSI Cycles

\section{INTRODUCTION}

Obesity and overweight are recognized as a growing global health problem Worldwide, prevalence of overweight or obesity, defined as an adult body mass index (BMI) of $25 \mathrm{~kg} \mathrm{~m}^{2}$ or greater, increased by $27.5 \%$ between 1980 and 2013. The proportion of overweight among adult women globally increased from $29.8 \%$ in 1980 to $38.0 \%$ in 2013 , notably in developing countries. Patterns of overweight and obesity differ between countries, regions and by country income, with overweight or obesity more prevalent among men in developed countries and among women in developing countries ${ }^{(1)}$.Measuring the amount of body fat was crucial in understanding the health of the individual along with the disease risk the individual is subjected to. One predictive method being used extensively in measuring the body fat in large population was Body Mass Index (BMI), a noninvasive and easy to accomplish method providing a good correlation with percentage body fat and level of risk. Measurement of body fat using weight relative to height, determines the BMI in $\mathrm{kg} / \mathrm{m}^{2}$.
BMI of an individual in the range of 20 and 24.9 is considered normal whilst between 25 and 29.9 was referred to as overweight. However, in obese individuals the BMI was greater or equal to 30. Despite the fact that BMI was certainly not flawless in providing an accurate body fat measurement, it has been used and proposed as a single indicator of body fat not only in adults_but also in children. However, BMI measurement does not provide the correct estimate of body fat in certain cases such as body builders, high performance athletes and pregnant women. Nevertheless, it still serves as a signal of obesity for clinical and screening purposes and maintaining a healthy lifestyle. Hence, the precise measurement of weight and height must be performed prudently ${ }^{(2)}$.Obesity has a significant negative effect on Intra Cytoplasmic Sperm Injection (ICSI) outcomes. Patients with BMI >30 have up to $68 \%$ lower odds of having a live birth following their first ART cycle compared with women with BMI $<30 \mathrm{~kg} / \mathrm{m}^{2}{ }^{(3)}$.Concerning ovarian stimulation, some authors had shown increased duration of 
stimulation, higher total dose of gonadotrophin administered. Lower ovarian response to ovarian stimulation, with reduced oocytes retrieval, poorer embryo quality and lower fertilization rates in obese women under-going in vitro fertilization (IVF) compared to normal weight infertile women However, other authors found no differences in IVF out-come according to female body mass index (BMI). Additionally, obese women who achieve conception after IVF are likely to present higher risks of spontaneous abortion and obstetrical complications ${ }^{(4)}$.A different means of investigating this issue is by focusing on the impact of weight loss on fertility. Weight reduction by any mean e.g. Diet or bariatric surgery, is without doubt, the most significant variable that dramatically improve fertility, menstrual cyclicity and reproductive outcomes (5).

\section{AIM of the WORK}

The study aimed to evaluate the impact of female increased body mass index (BMI) on implantation rate and clinical pregnancy in women undergoing ICSI cycle.

\section{PATIENTS and METHODS}

This was a retrospective study conducted on a total of 400 cycles of assisted reproduction treatment have been evaluated from Orabi IVF Centre and Mit_Ghamr IVF Centre.

\section{Inclusion criteria included:}

- Age: 20-40 years

- BMI: $>18 \mathrm{~kg} / \mathrm{m} 2$.

- Male factor: normal semen analysis.

- Underwent long agonist protocol.

Exclusion criteria included:

- $\mathrm{BMI}<18 \mathrm{~kg} / \mathrm{m} 2$.

- Age $>40$ years.

- FSH $>12 \mathrm{IU} / \mathrm{L}$.

- Women who had frozen embryo transfers.

- Woman with pelvic disease (Fibroid, PID, endometriosis, ovarian mass).

- Women with medical history (DM, HTN, Hyper and Hypothyroidism).

- Abnormal Hystrosalpingogram HSG. (Hydrosalpnix, pyosalpinx, septate, bicorniate uterus).

\section{Methods:}

- Data recruited from patient files from January 2016 to July 2018 who did ICSI trial during this period.

- Patients which included in our study are sub divided into 2 groups according to BMI:

- $1^{\text {st }}$ group: normal weight with BMI between 18 and $24.9 \mathrm{~kg} / \mathrm{m} 2$. (200 case).

$\circ 2^{\text {nd }}$ group: overweight and obese women $\geq 25 \mathrm{~kg} / \mathrm{m} 2$ (200 case).

- So we demonstrate the following in our 2 groups :

1. Age, weight, height, BMI.

2. The numbers and quality of the embryo transferred

3. Fertilization rate.

4. Pregnancy rate

5. Basal hormonal assay on 3rd day of cycle (Serum FSH, LH, E2, PRL and TSH)

6. Duration of stimulation.

7. Total dose and Number of ampoules of gonadotrophin administered.

8. Ovarian response. The size and numbers of the follicles.

9. The numbers and quality of oocyte retrieved.

\section{Statistical analysis}

Data were fed to the computer and analyzed using IBM SPSS software package version 22.0 Qualitative data were described using number (frequency) and Percent. Quantitative data were described using mean and standard deviation after testing normality using Kolmogorov-Smirnov test. Significance of the obtained results was judged at the 5\% level. All tests were 2-tailed. Categorical variables were compared using Chi square test, and continuous variables were compared using non-independent sample $t$ test or MannWhitney U test (expressed as z). For all above mentioned statistical tests done, the threshold of significance is fixed at 5\% level ( $\mathrm{p}$-value). The results was considered: Non-significant when the probability of error is more than $5 \%$ (p > 0.05 ), significant when the probability of error is less than $5 \%(\mathrm{p} \leq 0.05)$, highly significant when the probability of error is less than $0.1 \%$ $(p \leq 0.001)$. The smaller the $p$-value obtained, the more significant are the results.

\section{RESULTS}


Table 1: demographic data and duration of infertility in the two studied groups

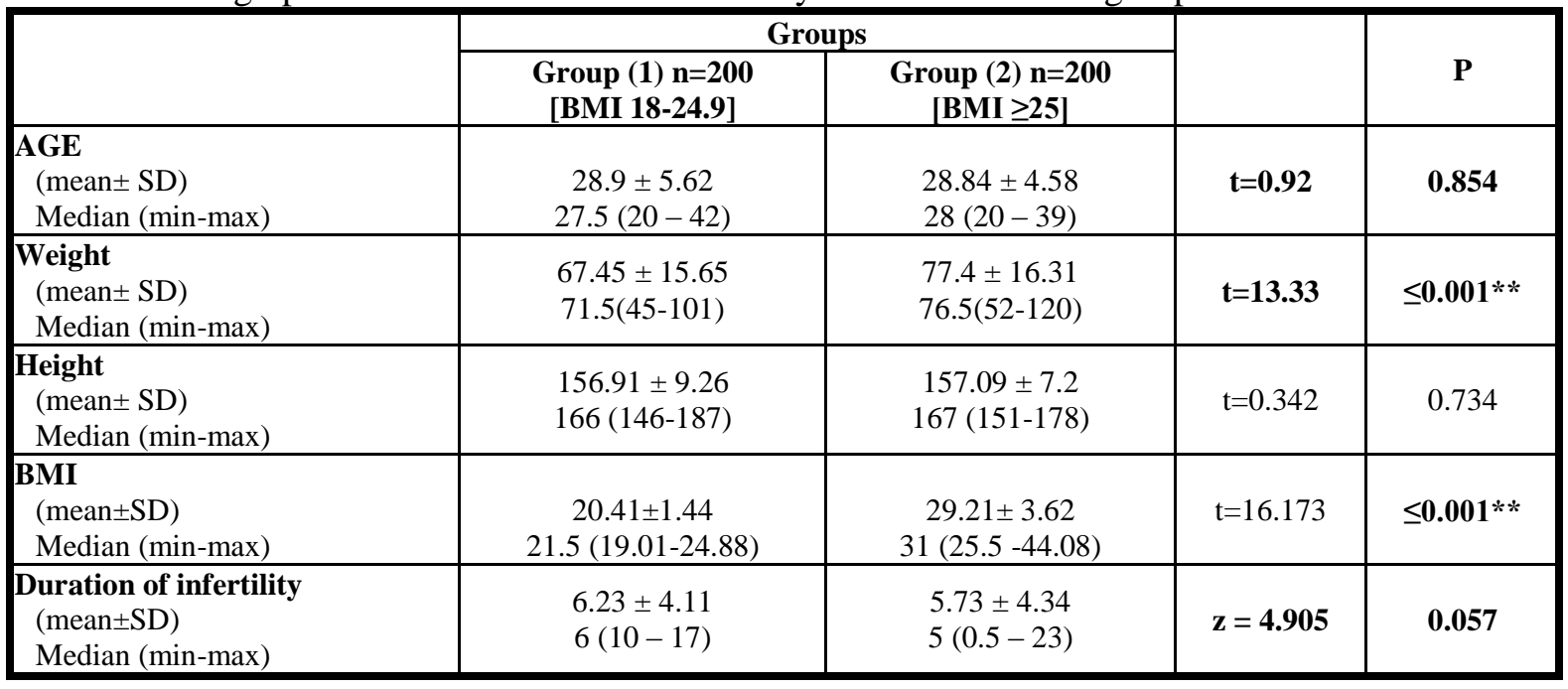

The two groups were comparable regarding female age were not statistically different in both groups. The duration of infertility showed no significant difference between the two groups. As in group (1) it range from 10-17 years with median duration of 6 years, while in group (2) it range from 0.5-23 with median duration of 5 years this result a significant difference with $p$ value(0.057).

Table 2: ovarian stimulation, oocyte and number of transferred embryo in the two studied groups

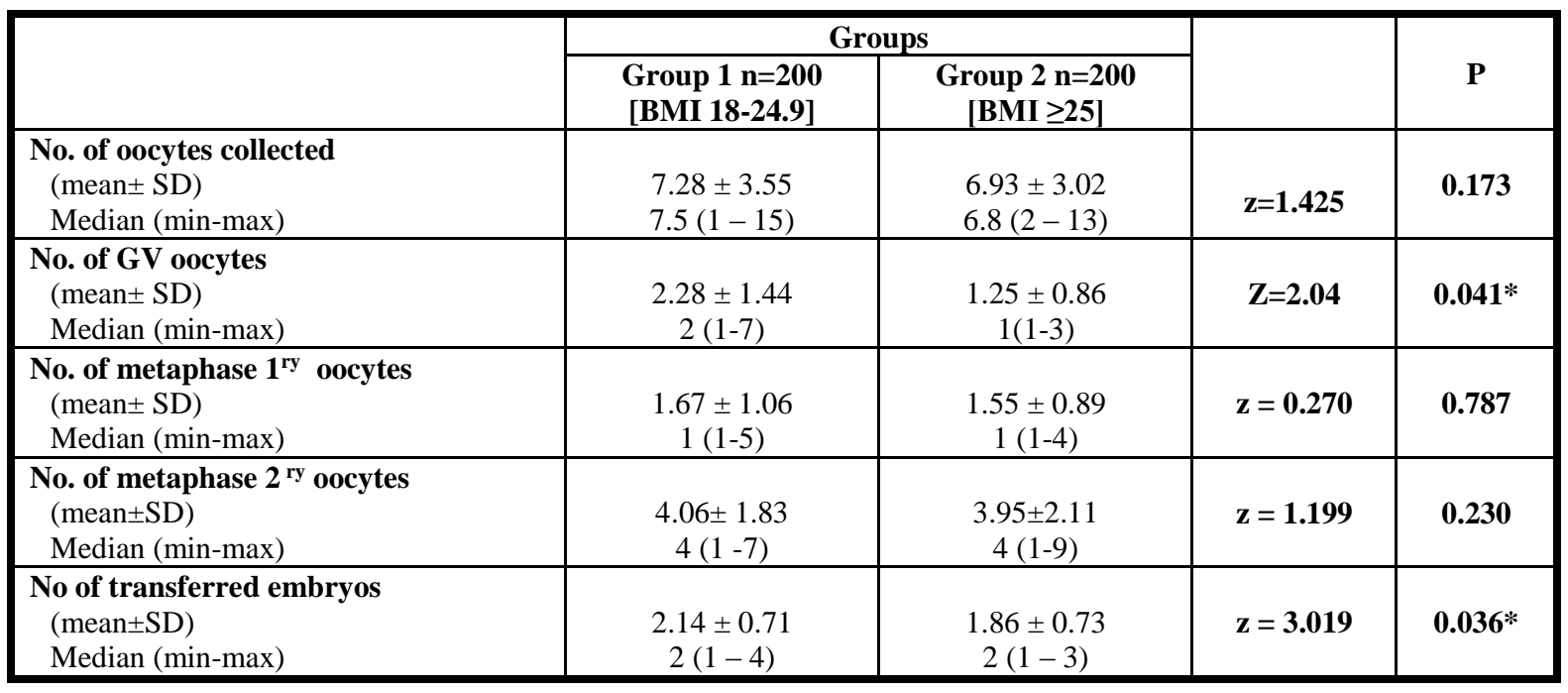

As showed in table 2 oocytes number and quality were found to be poorer in group 2 than in group 1 with only significant difference in the quality of collected oocytes ( $\mathrm{P}$ values $=0.041)$. Number of transferred embryo was higher in group 1 than group 2 ( $\mathrm{P}$ values $=0.036$ ).

Table 3: fertilization rates and quality of the embryos in the two studied groups

\begin{tabular}{|c|c|c|c|c|c|c|}
\hline & \multicolumn{4}{|c|}{ Groups } & & \multirow[b]{2}{*}{$\mathbf{P}$} \\
\hline & \multicolumn{2}{|c|}{$\begin{array}{c}\text { Group (1) } \mathrm{n}=200 \\
\text { [BMI 18-24.9] }\end{array}$} & \multicolumn{2}{|c|}{$\begin{array}{c}\text { Group (2) } n=200 \\
{[B M I \geq 25]}\end{array}$} & & \\
\hline \multicolumn{7}{|l|}{ Fertilization } \\
\hline & Number & percent & Number & percent & & \\
\hline Negative & 25 & $12.5 \%$ & 27 & $13.5 \%$ & & \\
\hline Positive & 83 & $41.5 \%$ & 65 & $32.5 \%$ & $\chi 2=7.62$ & $0.041^{*}$ \\
\hline \multicolumn{7}{|l|}{ Quality Grade A } \\
\hline & 172 & $86 \%$ & 151 & $75.5 \%$ & $\chi 2=17.71$ & $<0.0001^{* *}$ \\
\hline \multicolumn{7}{|l|}{ Quality Grade B } \\
\hline & 63 & $31.5 \%$ & 49 & $24.5 \%$ & $\chi 2=9.13$ & $0.012 *$ \\
\hline
\end{tabular}


The rate of successful fertilization and quality of transferred embryos of both grades A\&B were significantly higher in group 1 as compared to group 2 (p values were $0.041,<0.0001$ and 0.012 respectively). These data were shown in details in table 3.

Table 4: percentage of the pregnancy occurrence in the two studied groups

\begin{tabular}{|l|c|c|c|c|c|c|}
\hline \multirow{2}{*}{} & \multicolumn{9}{|c|}{ Groups } & \multirow{2}{*}{ P } \\
\cline { 2 - 5 } & \multicolumn{2}{|c|}{$\begin{array}{c}\text { Group (1) n=200 } \\
{[\text { BMI 18-24.9] }}\end{array}$} & $\begin{array}{c}\text { Group (2) } \mathbf{n = 2 0 0} \\
{[\text { [BMI } \geq \mathbf{2 5}]}\end{array}$ & \\
\hline & Number & percent & Number & percent & \\
\hline
\end{tabular}

As shown in the previous table the percentage of positive pregnancy was very highly significant in group 1 than in group 2. (P value is $<0.0001$ )

Table 5: basal hormonal profile in the two studied groups

\begin{tabular}{|c|c|c|c|c|}
\hline & \multicolumn{2}{|c|}{ Groups } & & \multirow[t]{2}{*}{$\mathbf{P}$} \\
\hline & $\begin{array}{c}\text { Group (1) } n=200 \\
\text { [BMI 18-24.9] }\end{array}$ & $\begin{array}{c}\text { Group (2) } n=200 \\
{[B M I \geq 25]}\end{array}$ & & \\
\hline $\begin{array}{l}\text { FSH } \\
(\text { mean } \pm \text { SD })\end{array}$ & $6.22 \pm 1.07$ & $6.44 \pm 1.21$ & $z=0.597$ & 0.551 \\
\hline $\begin{array}{l}\mathbf{L H} \\
(\text { mean } \pm \mathrm{SD})\end{array}$ & $4.95 \pm 1.15$ & $5.18 \pm 1.26$ & $z=1.331$ & $0.047 *$ \\
\hline $\begin{array}{l}\text { PRL } \\
\quad(\text { mean } \pm \text { SD })\end{array}$ & $15.78 \pm 2.76$ & $15.6 \pm 2.76$ & $z=1.697$ & 0.11 \\
\hline $\begin{array}{l}\text { Basal E2 } \\
(\text { mean } \pm \text { SD })\end{array}$ & $48.41 \pm 4.92$ & $61.84 \pm 4.91$ & $\mathrm{z}=\mathbf{3 . 0 8 8}$ & $0.002 * *$ \\
\hline $\begin{array}{l}\text { TSH } \\
(\text { mean } \pm \text { SD) } \\
\text { Median (min-max) }\end{array}$ & $5.33 \pm 1.36$ & $5.04 \pm 1.69$ & $\mathrm{z}=1.432$ & 0.09 \\
\hline
\end{tabular}

Table 5 showed basal hormonal status on day 3 showed that group 2 patients had a higher FSH level than group 1 but, this difference was minimal, belonging to reference interval and thus without clinical significance However, significantly lower day 3 estradiol (E2) (P-value: 0.002*) and LH levels (P-value: $0.047^{*}$ ) in group 2 than group 1 . There was no significant difference between the median level of PRL and TSH between the two groups.

Table 6: ovarian stimulation, ovarian response in the two studied groups

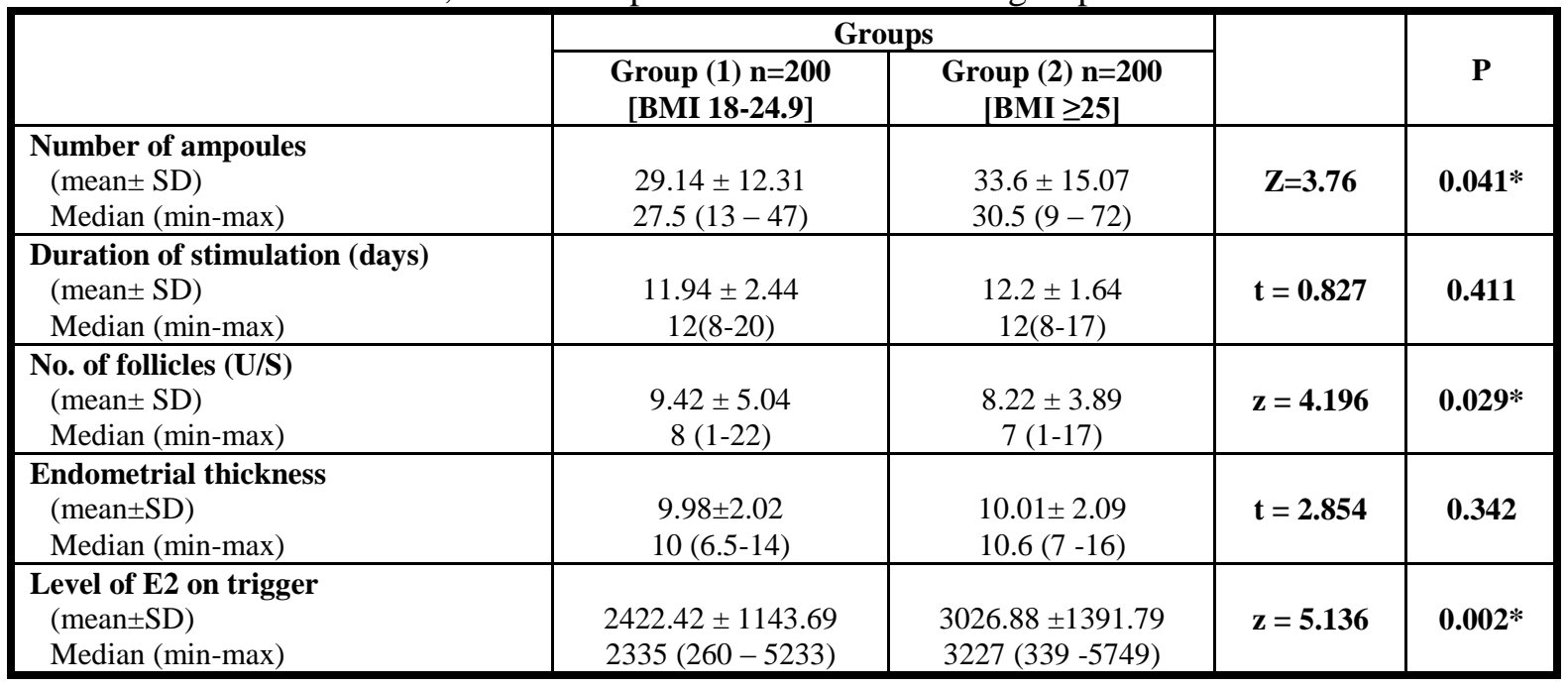

ICSI cycle outcomes were reported in table 6. Overweight and obese patients (Group
2) received significantly higher doses of induction ampoules when compared to group 1 
(p-value $=0.041)$, leading to comparable ovarian response, with significant difference in the number of mature oocytes as revealed by $\mathrm{U} / \mathrm{S}$ between the two groups $(\mathrm{p}$-value $=0.029)$. Duration of stimulation and endometrial thickness were not statistically different between group 1 and group 2. Serum estradiol level on ovulation triggering day was significantly higher in group 2.

\section{DISCUSSION}

The development and refinement of assisted reproductive technology (ART) over the last decades coincided with a rapid increase in the prevalence of obesity among women of reproductive age ${ }^{(6)}$. Therefore, the present study aimed to estimate the effect of BMI on implantation rate and clinical pregnancies in women undergoing their ICSI cycle.In the current study, distribution of the studied sample according to BMI of the females showed that patients were categorized into two groups

- Group 1: normal weight with BMI between 18 and $24.9 \mathrm{~kg} / \mathrm{m}^{2}$. (200 case) with their mean BMI 20.41 (standard deviation 1.44 , range 19.01 - 24.88).

- Group 2: overweight and obese women $\geq$ $25 \mathrm{~kg} / \mathrm{m}^{2}$ (200case). With their mean BMI 29.21 (standard deviation 3.62, range 25.56-44.08). With significant difference between the two groups. P-value $\left(\leq 0.001^{* *}\right)$.In our studied group the duration of infertility was progressively higher as BMI increased. The two groups were comparable regarding female age were not statistically different in both groups. The duration of infertility showed no significant difference between the two groups. As in group 1 it ranged from 10-17 years with median duration of 6 years, while in group 2it ranged from $0.5-23$ with median duration of 5 years this result a significant difference with $\mathrm{p}$ value (0.057).This agrees with study carried out by Bellver et al. ${ }^{(7)}$; it was a larger retrospective study of over 6,000 women, which showed a delayed spontaneous conception that has been reported in obese women, mainly caused by a higher risk of ovulatory infertility, but also in women with regular ovarian cycles in whom the probability of pregnancy was reduced by $5 \%$ for every unit of BMI that exceeded 29 $\mathrm{kg} / \mathrm{m}^{2}$. with $\mathrm{p}$ value $(0.024)$. We showed that overweight and obese infertile women had a higher basal serum FSH, LH and estradiol levels than normal weight women. This observation is in harmony with a previous study that also found impaired pulsatile secretion of pituitary gonadotrophin in obese women, leading to impaired folliculogenesis ${ }^{(8)}$.However, another disagrees with our finding ${ }^{(9)}$. Also, the important observation drawn from our study is the need for higher doses of gonadotrophin for ovarian stimulation in overweight and obese women compared to normal weight women. This highlighting a special state of "gonadotropin resistance". This state leads to longer periods of ovarian stimulation.Most studies conducted in obese women undergoing IVF cycles agree with us and reported the same observation ${ }^{(3,7,10)}$.Raising several hypotheses. First, this increased dose requirement of gonadotrophin may be related to altered pharmocodynamics characteristics of drugs administered subcutaneously in obese women having increased subcutaneous fat thickness. Indeed, changes in absorption, metabolism, bioavailability and clearance have been reported in these women ${ }^{(4)}$.

In addition, our study noted that E2 levels in the HCG day were significantly higher in patients with higher BMI when compared to women with lower BMI.

This in harmony with the study done by Rittenberg et al. (11), but disagrees with the study done by Moragianni et al. ${ }^{(3)}$ and Caillon et al. (4) who aimed to provide assisted reproductive technology (ART) outcome rates per body mass index (BMI) category. In their study, higher BMI was associated with lower E2 levels in the day of HCG.Several hypotheses have been raised, involving the relative hyperoestrogenaemia state or hyperinsulinaemia and some pro-inflammatory cytokines (IL-6, TNF-) which could create an unfavorable uterine environment for embryonic implantation. This low-grade inflammatory state has also been related to polycystic ovarian syndrome, independently of obesity ${ }^{(\mathbf{1 2})}$.In our study, embryo quality and implantation rates were higher in normal weight than in obese women. This remains controversial in the literature, but conversely some authors did not find any effect of obesity upon implantation rate in IVF cycles ${ }^{(\mathbf{1 3})}$. Our study found that 
oocytes number and quality were poorer in group 2 than in group 1, Number and quality of transferred embryo was higher in group 1 than group $2(\mathrm{P}=0.003)$, and subsequently clinical pregnancy rate tended to be poorer in group 2 than in group 1, (although not significant).In a retrospective study which was done by Nichols et al. ${ }^{(14)}$ showed that the dose of gonadotrophin used, the number of oocytes retrieved, the number and quality of embryos transferred and the miscarriage rate did not differ between the BMI groups. However, implantation and pregnancy rates were lower in the BMI > 25 $\mathrm{kg} / \mathrm{m} 2$ group than in the normal weight group.Contrarily, another study reported a detrimental effect of increased female BMI on ovarian response to stimulation, lower number of oocytes retrieved and lower number of embryos transferred ${ }^{(\mathbf{1 1})}$. As many variables can impact Implantation Rate \& IVF success rates, our observations on obesity must be interpreted in light of other factors, such as age, to establish treatment strategy. A study demonstrated that BMI had a minimal impact on fertility compared to age in women aged35 years or more. Beyond these biological and clinical implications, treatment of infertile overweight and obese women has a deep medico-economic impact ${ }^{(15)}$.Nevertheless, to our knowledge, there is not enough evidence to determine BMI threshold permitting or delaying care of infertility, It is essential to stress losing weight in obese women younger than 35 years by physical activity and hypo caloric diet or medical treatment. It has already been shown that weight loss from $5 \%$ can improve menstrual cyclicity and reproductive outcomes ${ }^{(5)}$.The controversy over ART outcome in obese patients may be due to different cut-off values used to define obesity, inclusion of patients with different infertility aetiologies and/or varying focused of outcome measures ${ }^{(16)}$.

\section{CONCLUSION}

Female overweight and obesity appeared to have deleterious effects on ovarian response for stimulation in women underwent IVF and on implantation rate. Moreover, female obesity compromised IVF outcome.

\section{REFERENCES}

1. Rahman MM, Abe SK, Kanda $M$ and Narita $S$ (2015): Maternal body mass index and risk of birth and maternal health outcomes in low and middle income countries: a systematic review and meta analysis. Obesity Reviews, 16(9) :758-770.

2. Omair SM, Shamim MF, Desai A and Shahid N (2018): Digital and analog body mass index calculating device: a comparative study. Indian Journal of Science and Technology, $\quad$ 10(45). 10.17485/ijst/2017/v10i45/120632.

3. Moragianni VA, Jones SM, Ryley DA et al. (2012): The effect of body mass index on the outcomes of first assisted reproductive technology cycles. Fertil . Steril., 98(1):102108 .

4. Caillon H, Fréour T, Bach-Ngohou K et al. (2015): Effects of female increased body mass index on in vitro fertilization cycles outcome. Obes . Res . Clin . Pract., 9(4):382-388.

5. Kort JD, Winget C, Kim SH et al. (2014): A retrospective cohort study to evaluate the impact of meaningful weight loss on fertility outcomes in an overweight population with infertility. Fertil . Steril., 101(5):1400-1403.

6. Flegal KM, Carroll MD, Ogden CL and Curtin LR (2010): Prevalence and trends in obesity among US adults, 1999-2008. JAMA., 303(3):235-241.

7. Bellver J, Ayllon Y, Ferrando M et al. (2010): Female obesity impairs in vitro fertilization outcome without affecting embryo quality. Fertil . Steril., 93(2):447-454.

8. De Pergola G, Maldera S, Tartagni M et al. (2012): Inhibitory effect of obesity on gonadotropin, estradiol, and inhibin B levels in fertile women. Obesity, 14 (11):1954-1960.

9. Dechaud H, Anahory T, Reyftmann L et al. (2006): Obesity does not adversely affect results in patients who are undergoing in vitro fertilization and embryo transfer. Eur . J. Obstet. Gynecol. Reprod . Biol., 127 (1):88-93.

10. Jungheim ES, Lanzendorf SE, Odem RR et al. (2009). Morbid obesity is associated with lower clinical pregnancy rates after in vitro fertilization in women with polycystic ovary syndrome. Fertil . Steril., 92(1):256261.

11. Rittenberg V, Seshadri S, Sunkara SK et al. (2011): Effect of body mass index on IVF treatment outcome: an updated systematic review and meta-analysis. Reprod. Biomed. Online, 23 (4):421-439. 
12. Brewer CJ and Balen AH (2010): The adverse effects of obesity on conception and implantation. Reproduction, 140 (3):347-364.

13. Haghighi $Z$, Rezaei $Z$ and Es-Haghi A $S$ (2012): Effects of women's body mass index on in vitro fertilization success: a retrospective cohort study. Gynecol . Endocrinol., 28 (7):536-539.

14. Nichols JE, Crane MM, Higdon HL et al. (2013): Extremes of body mass index reduce in vitro fertilization pregnancy rates. Fertil . Steril., 79 (3):645-647.

15. Sneed ML, Uhler ML, Grotjan HE et al. (2012): Body mass index: impact on IVF success appears agerelated. Hum . Reprod., 23(8):18351839.

16. Ozgun MT, Uludag S, Oner G et al. (2011): The influence of obesity on ICSI outcomes in women with polycystic ovary syndrome. J. Obstet . Gynaecol., 31(3): 245-249. 